\title{
Study of water salinity effect on geotechnical behavior of soil structure using response surface method (RSM), (Case study: Gotvand Dam)
}

\author{
Mohammad Ajam¹, Mohammad Reza Sabour², Gorban Ali Dezvareh³ \\ ${ }^{1}$ M.Sc. of Civil \& Environmental Engineering, K.N.Toosi University of Technology, \\ Tehran, Iran \\ ${ }^{2}$ Associate Professor of Civil \& Environmental Engineering Faculty, K.N.Toosi University of \\ Technology, Tehran, Iran \\ ${ }^{3} \mathrm{Ph}$. D. Candidate of Civil \& Environmental Engineering, K.N.Toosi University of Technology,
} Tehran, Iran

\begin{abstract}
Specifying the mechanical characteristics of soil is as one of the major steps in designing the foundation for civil projects, particularly hydraulic structures. This study examines the water salinity effect on engineering characteristics of fine-grained soil in clayey core of Gotvand dam which it is located on the Karun River in Khuzestan province, Iran. For this purpose, three types of salt; sodium chloride, magnesium chloride and calcium sulfate is considered that the last one has the highest concentration in the water of reservoir behind the dam, and then their effect on the mechanical characteristics of clay including density, Atterberg limits, angel of internal friction, adhesion and open inflation have examined. Therefore, treatments required for testing were provided by combining the mentioned salts considering the weight percentage of salt in the water behind the dam and designing a test using response surface methodology (RSM). The results were statistically analyzed by RSM. Results showed that type and amount of soil salinity has no significant impact on the compaction characteristics of soil namely optimum moisture content and the maximum dry density. Results of changes in Atterberg limits showed that presence of salt ions reduces the plasticity of the soil and it was seen a certain decrease in the liquid limit and subsequently a dramatic drop in soil plasticity by increasing the percentage of soil; while the plastic limit remained almost unchanged. Eventually, results of open inflation showed that whatever the salt concentration be higher, the rate of sample's open inflation will be lower.
\end{abstract}

Kew words: Gotvand dam, Water salinity and soil open inflation, Density characteristics, Plasticity properties, RSM. 


\section{Introduction}

Engineering characteristics of fine-grained soils especially clayey soils are subject to several factors including density, porosity, structure, history of tension, granulation, amount and type of clayey minerals, plastic property and amount and kind of minerals in the pore water [1]. Any change in each of these characteristics will change the physical and mechanical characteristics of soil, and consequently structures which are built on soil will exposed to change or threat. Density, shear strength and plasticity are considered as characteristics of soil engineering which play an important role in designing foundation of most civil structures [2]. Basically, theories of soil mechanic are based on the concept of effective stresses. In these theories the pore water and solid particles are both assumed to be chemically inert, so no chemical interaction takes place between the different phases. While, due to the negative charge on the surface of clayey mineral particles, electrochemical forces exist between the solid, liquid and dissolved phases that they can mainly change the mechanical behavior of clayey soil [3]. The quantity and nature of electro-chemical forces and consequently changes in properties of soil depends on the amount and type of anion and cation in exchange phase and their impact on the cation exchange capacity [4].

Any change in soil engineering properties can cause changes in the parameters used in designing soil structures, civil and water related constructions and other structures' foundations. So, determining the behavior and reaction of soil under the influence of solutions and different materials can be effective in designing and making the correct decisions. Type of chemicals that are combined with clayey soil and also its constituents are considered as one of the important issues to understand changes in soil engineering properties [5].

This study has examined Gotvnd dam as the case study. Upper Gotvand dam is one of Iran's largest dams which it is built on Karun River, southwest of Iran. This dam is located at the distance of $380 \mathrm{~km}$ from the outfall of the Karun river, at the distance of $25 \mathrm{~km}$ from north of Shushtar city and at the distance of $10 \mathrm{~km}$ from northeast of Gotvand city in Khuzestan province. It is the last dam which can be constructed on the Karun River. This dam's lake has a reservoir of 4.5 billion cubic meters which makes it the second largest artificial lake in Iran after karkhe dam. The Gotvand dam is a rock fill dam with clay core and a height of 182 meters which makes it the largest earthen dam of the country. Executive operations of this project have begun in 1976. This dam is located more downstream among the built dams and dams that are currently under construction on the Karun River.

The salt domes and veins around the inundation area of dam is one of the major challenges about the dam which it goes under water after inundation and leads to excessive salinity of water in downstream of this dam. Experts of environment and engineering council believe that closeness of salt mine and Gachsaran's salt formation to the site of the Upper Gotvand dam is not considered in this research project. This mine is located $5 \mathrm{~km}$ away from the dam and its salt has been estimated hundreds of million tons. During inundation and formation of the lake behind the dam, this mine has gone completely under water and caused that the salinity of Karun River's water reaches to the highest possible extent. The passage of time proved that inundation of this dam has led to the salinity of Karun River about 10 times. After the construction operation and before beginning the inundation, constructors proceed to build a clay blanket on the salt formations. But, signs of cracking were observed on clay blanket just three days after the edges of these blankets went under water. Investigating the water behind the dam showed that the blankets had no effect on reducing the amount of water salinity. Figure 1 shows an overview of the dam.

Considering the current situation, it seems that the following problems are predictable in this dam:

1. Extreme ruin and change in the quality of water in the dam's lake 
2. The instability of Gachsaran's formation and creating large landslides in the dam's reservoir

3. The damaging effects of water salinity on the dam's body in long-term

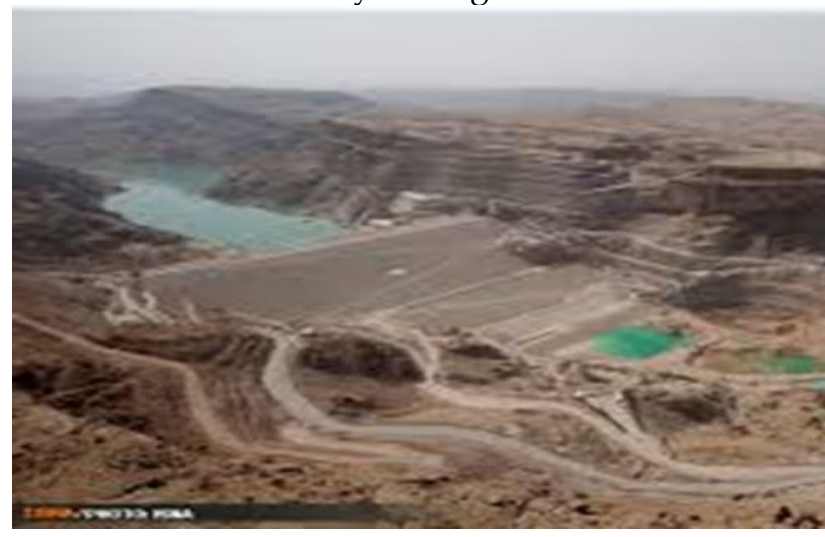

Figure 1: a view of Gotvand

This study investigates the damaging effects of water salinity on the dam's body and the clayey lands around the lake, to investigate the possibility of slippage, by studying the impact of pore water salinity on the mechanical properties of clayey soil.

Various researches have conducted scattered and diverse researches on investigating and determining the effect of different salts and solutions on the engineering properties of clayey soils. Lambe (1985) states that in a certain porous ratio, any change in the water-soil system that inflates the dual layer will reduce the resistance [6]. Mitchell (1993) believes that in addition to the type and amount of clay in the soil, its chemical characteristics such as the amount and type of anion and the existing cations have a substantial impact on the physical and mechanical behavior of soil such as construction, aggregate instability, consolidation and especially inflation [7]. Abdullah et al. (1997) have investigated the impact of sodium, calcium and potassium on the consolidation characteristics of clayey soils [8]. Van Paassen et al. (2004) have examined the impact of pore water salinity on the clayey soil compaction [8]. Yilmaz (2006) showed that there is an appropriate relationship between cation exchange capacity and mechanical properties such as inflation and liquid limit [9]. Yukselen et al. (2008) claim that soils engineering behavior varies depending on the type of clay minerals. So that, properties of Montmorillonite clays strongly change against the sea water [10]. Rao and Thyagaraj (2007) investigated the effect of sodium chloride solution on inflation behavior of compacted clayey soil by using consolidation test [11]. Baumgartner et al. (2008) suggested that calcium chloride reduces the potential for inflation [12]. Olson and Mitronovas (1960) figured out that the electrolyte concentration has little effect on the Atterberg limits by examining the consolidation characteristics and shear strength of calcium and magnesium illites[13]. The study results from Kenny (1967) and Moore (1991) suggest that the resistance of remaining clays depends on the type of minerals and the chemical properties of pore water [14]. Chatopad haya (1972) measured the shear strength remaining from samples of Montmorillonite clays that had been affected by salt water and he showed that the remaining shear strength will rise by increasing the concentration of water [15]. D Maio (1994) also finds similar results. D Maio conducted some tests on the liquid limit of disturbed samples of Bentonite with $\mathrm{NaC1}$ and he observed that liquid limit will decrease rapidly by increasing the salt concentration [16]. Mashkouh (2011) examined the impact of salt and moisture on mechanical properties of clayey soil [17]. Abbasi (2013) also investigated the effect of pore water salinity on the consolidation and compaction properties of clayey soil [18].

This study also investigates the effect of pore water salinity on some geotechnical characteristics of clayey soil by considering the abundant use of clayey soils in the foundations' structures, due to the high compressibility, and also the main body of embankment dams and high level of water salinity in the vast areas of the world, including Iran.

\section{Materials and Methods}

This study is used samples with different salinity level to investigate the effect of pore water salinity on geotechnical characteristics of clayey soil. For this purpose, at first a sample of clayey soil with the physical properties in table 1 is prepared from Emam -zadeh Zeid borrow source near the Gotvand dam. Then, the experimental treatments were made by adding different amounts of salt, sodium chloride, magnesium chloride and calcium sulfate. After preparing the sample of natural soil, different 
amounts of ionic composition containing the mentioned salts was added to the samples in the ratio of zero to eleven percent by weight in order to obtain a sample with the desired chemical characteristics. Then, the test designed by using RSM.
Finally, the results of measurements were analyzed statistically using RSM and final versions and graphs were extracted from this software. Table 1 shows the characteristics of salts used in this project.

Table 1: characteristics of salts used in this project

\begin{tabular}{|c|c|c|c|c|c|c|}
\hline Salt & $\begin{array}{c}\text { Molecular } \\
\text { formula }\end{array}$ & appearance & $\begin{array}{c}\text { Molar } \\
\text { mass }\end{array}$ & Density & $\begin{array}{c}\text { Melting } \\
\text { temperature }\left({ }^{\circ} \mathrm{C}\right)\end{array}$ & $\begin{array}{c}\text { Solubility in } \\
20^{\circ} \text { water }\end{array}$ \\
\hline $\begin{array}{c}\text { Sodium } \\
\text { chloride }\end{array}$ & $\mathrm{NaCl}$ & $\begin{array}{c}\text { Colorless or } \\
\text { white crystal }\end{array}$ & 58.44 & 2.16 & 801 & 35.9 \\
\hline $\begin{array}{c}\text { Magnesium } \\
\text { chloride }\end{array}$ & $\mathrm{MgCl} 2$ & $\begin{array}{c}\text { Colorless or } \\
\text { white crystal }\end{array}$ & 95.211 & 2.32 & 714 & 54.3 \\
\hline $\begin{array}{c}\text { Calcium } \\
\text { chloride }\end{array}$ & CaSo4 & White solid & 136.14 & 2.96 & 1460 & 0.21 \\
\hline
\end{tabular}

At first, the percentage of salt used in the new salt composition was determined according to the water behind the dam in order to build the samples. Salts were combined according to the specified weight percentage. The new salt composition was combined with the dry soil completely homogenous by using the software according to the specified weight percentage; then, the necessity moisture content was added to the samples.
Table 2 gives the characteristics of percentage of salts used in samples according to renewed designing the software.

The ratio of sodium chloride, magnesium chloride and calcium sulfate percentage to the total salt is considered with a little overlook, respectively 50,30 and 20 .

Table 2: Characteristics of percentage of salts used in samples according to renewed designing the software

\begin{tabular}{|c|c|c|c|c|}
\hline $\begin{array}{c}\text { Designed } \\
\text { tests }\end{array}$ & $\begin{array}{c}\text { Weight percentage of ionic } \\
\text { composition to the soil }\end{array}$ & $\begin{array}{c}\text { Weight percentage } \\
\text { of Nacl to the soil }\end{array}$ & $\begin{array}{c}\text { Weight percentage of } \\
\text { Mgcl2 to the soil }\end{array}$ & $\begin{array}{c}\text { Weight percentage of } \\
\text { Caso4 to the soil }\end{array}$ \\
\hline 1 & 5.5 & 2.75 & 1.65 & 1.1 \\
\hline 2 & 8.25 & 4.125 & 2.475 & 1.65 \\
\hline 3 & 0 & 0 & 0 & 0 \\
\hline 4 & 2.75 & 1.375 & 0.825 & 0.55 \\
\hline 5 & 11 & 5.5 & 3.3 & 2.2 \\
\hline 6 & 0 & 0 & 0 & 0 \\
\hline 7 & 11 & 5.5 & 3.3 & 2.2 \\
\hline
\end{tabular}

\section{Diagnostic Tests}

Initial tests including granulation, determining Atterberge limits, dry density and also extracting chemical properties of soil were done according to ASTM in order to identify and determine the physical characteristics of used natural soil. Table 3 shows the physical and chemical characteristics of used soil.

Table 3: Characteristics of Initial Soil

\begin{tabular}{|c|c|c|c|c|c|c|c|c|c|}
\hline 总 & 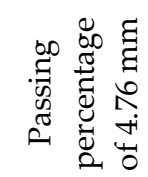 & 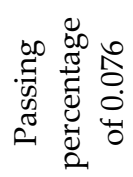 & 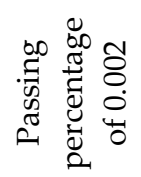 & 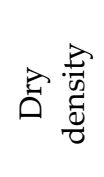 & 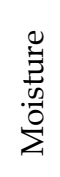 & 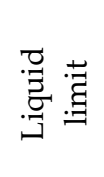 & 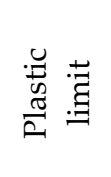 & 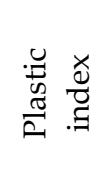 & $\stackrel{\mathbb{I}}{\Sigma}$ \\
\hline
\end{tabular}




\begin{tabular}{|l|l|l|l|l|l|l|l|l|l|}
\hline CL & 100 & 95 & 25 & 1.29 & 4.55 & 55 & 18 & 37 & 7.4 \\
\hline
\end{tabular}

\section{Open inflation test}

Inflation test was carried out based on ASTMD4546 standard and through method (A). In this method, the amount of soil sample inflation under the initial overload of apparatus, $1 \mathrm{kPa}$, was measured over time. Parameters measured in this test have a high percentage.

\section{Density Testing}

Compaction characteristics of soils including dry unit weight and optimum moisture are as the important characteristics of soil in engineering issues such as the constructing embankments related to the paths of channels, roads, bodies of dams and other similar cases. These characteristics can be determined by testing density of sample. This research is used standard proctor test provided in ASTM for determining the characteristics. So that, sample was compacted in three layers and each layer with 25 beats with various moisture content.

\section{Atterberge Limits Testing}

Atterberge limit is a defined criterion for the moisture content of soil.The test was conducted on samples according to the ASTMD4318 standard which noted above. Figure 2 shows Casagrande cup in order to get the liquid limit and figure 3 shows plasticity test to get the plastic limit.

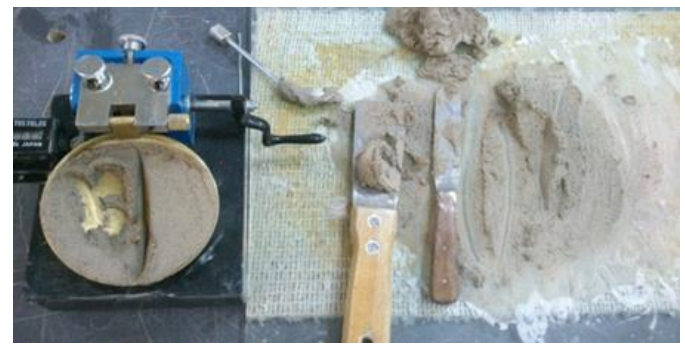

Figure 2: Casagrande cup

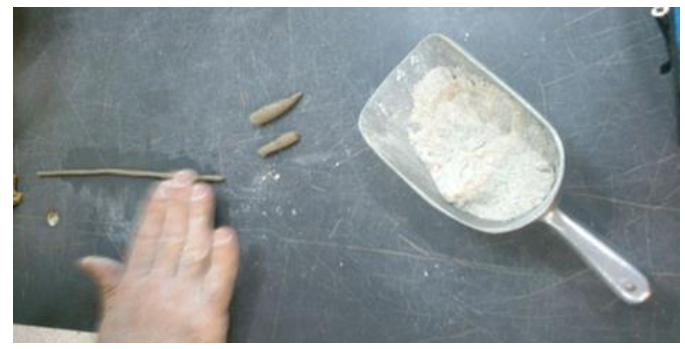

Figure 3: plasticity test

\section{Designing the Test}

Designing the test was done with regard to the two factors, moisture content and salt, to test the open inflation by using RSM. Figure 4 shows designing the test by software for Open Inflation Test.

\begin{tabular}{|r|r|r|r|r|r|} 
Std & Run & Block & $\begin{array}{c}\text { Factor 1 } \\
\text { Aisat } \\
\%\end{array}$ & \multicolumn{1}{|c|}{$\begin{array}{c}\text { Factor 2 } \\
\text { Bimoist } \\
\%\end{array}$} & \multicolumn{1}{c|}{$\begin{array}{c}\text { Response } \\
\text { sw } \\
\%\end{array}$} \\
\hline 4 & 1 & Block1 & 9.39 & 22.07 & 6.1 \\
\hline 3 & 2 & Block1 & 1.61 & 22.07 & 9.7 \\
\hline 1 & 3 & Block 1 & 1.61 & 7.93 & 21.6 \\
\hline 2 & 4 & Block 1 & 9.39 & 7.93 & 15.9 \\
\hline 7 & 5 & Block1 & 5.50 & 5.00 & 18.5 \\
\hline 5 & 6 & Block 1 & 0.00 & 15.00 & 14.4 \\
\hline 6 & 7 & Block 1 & 11.00 & 15.00 & 4.8 \\
\hline 8 & 8 & Block 1 & 5.50 & 25.00 & 7.5 \\
\hline
\end{tabular}

Figure 4: Designing the test with regard to the two factors of salt concentration and moisture Also, figure 5 shows designing the software to test Atterberge Limits and density considering the factor of increasing concentration.

\begin{tabular}{|c|c|c|c|c|c|c|c|c|}
\hline Sto & Run & Block & $\begin{array}{c}\text { Factor } 1 \\
\text { ACA }\end{array}$ & $\begin{array}{c}\text { Response } \\
\text { yd } \\
\text { yents }\end{array}$ & $\begin{array}{c}\text { Responst } \\
\text { wost } \\
y\end{array}$ & $\begin{array}{c}\text { Ressomse. } \\
4 \\
5\end{array}$ & $\begin{array}{c}\text { Ressonse } \\
\text { P. } \\
\text { s. }\end{array}$ & $\begin{array}{c}\text { Resposese } \\
\text { A } \\
y\end{array}$ \\
\hline & 1 & Block1 & 5.50 & 16 & 119 & 4.7 & 189 & 248 \\
\hline 4 & 2 & Block 1 & 8.25 & 1.4 & 122 & 40. & 191 & 213 \\
\hline 1 & 3 & Block 1 & 0.00 & 133 & 123 & ts & 18 & 37 \\
\hline 3 & 4 & Block 1 & 2.75 & 16 & 119 & 51.3 & 183 & 33 \\
\hline 6 & 5 & Block 1 & 11.00 & 1,45 & 118 & 381 & 19.4 & 187 \\
\hline 2 & 6 & Block 1 & 0.00 & 15 & 12 & 54 & 185 & 35.5 \\
\hline 5 & 1 & Block 1 & 11.00 & 1.37 & 1118 & 385 & 19 & 195 \\
\hline
\end{tabular}

Figure 5: Redesigning the test based on the one factor model

\section{Results and Discussions}

After running the relevant tests on the samples in question, characteristics of each treatment was determined, then the role of chemical quality of samples on the noted characteristics was analyzed. Designing the test for open inflation 
was done with regard to the two factors of moisture and salt, and this test's results were analyzed.

\section{Open Inflation Test}

The results of this test are presented in the column Sw of figure 4. Data analysis was done by RSM. Figure 6 shows the simultaneous effect of increasing the percentage of salt and moisture.
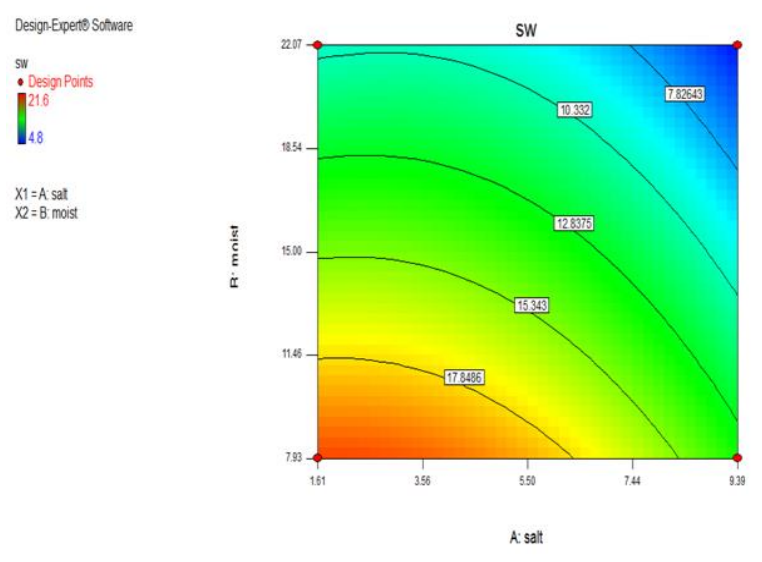

Figure 6: The simultaneous effect of increasing the percentage of salt and moisture on open inflation

As it can be seen in figure 6, whatever the salt concentration is higher, the rate of sample's open inflation will be lower. This reduction in open inflation percentage applies in all points of the curve with different moistures percentage.

The percent of open inflation is reduced by increasing the percent of moisture. According to the preliminary tests, the optimum soil moisture content is about 12 percent. According to the level of response presented in figure 10, it can be seen that samples with dryer moisture content from optimum moisture have more inflation than more wet points from optimum point, and this matter is apart from the percent of salt.

Also the samples which were exposed to the higher salinity shows less sensitivity to increasing the moisture content.

Inflationary behavior of the soil in contact with salt waters is mainly analyzed with regard to factors: disseminating saline minerals into the soil and reducing the double layer thickness of soil. Figure 7 and 8 shows the minimum and maximum open inflation mode, respectively. According to the figures, the lowest inflation occurs when the percent of moisture and salt is at the highest level and the highest percent of open inflation occurs when the percent of moisture and salt concentration is at the lowest level.

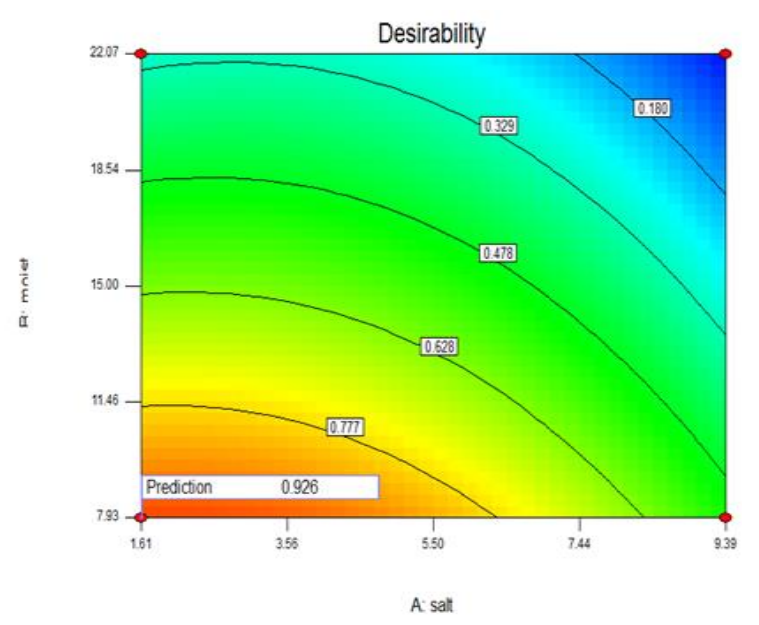

Figure 7: The lowest percent of open inflation

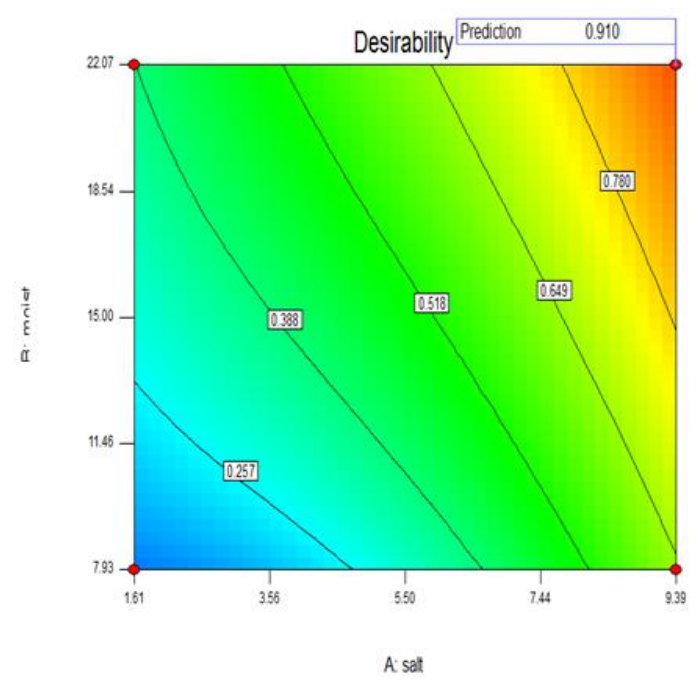

Figure 8: The highest percent of open inflation

\section{Atterberge Limits Test}

Figure 9 shows the relationship between the percent of salt and the plastic limit. As it can be seen, the plastic limit will increase slightly by increasing the salt. 

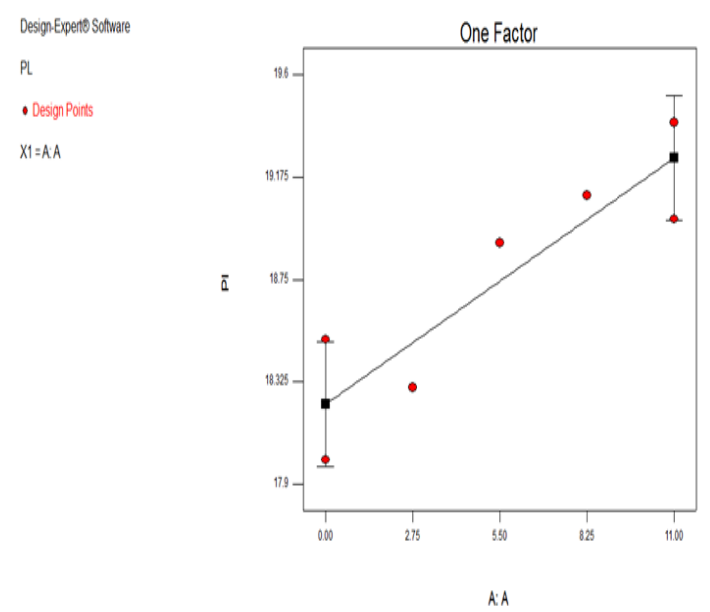

Figure 9: The curve diagram of changes in the plastic limit against the percent of salt

RSM model is given in the following to predict the amount of plastic limit.

$\mathrm{PL}=18.23+0.09292^{*} \mathrm{~A}$

Also, figure 10 shows the relationship between increasing the percentage of salt and liquid limit. As it can be seen, the liquid limit will decrease by increasing the salt.

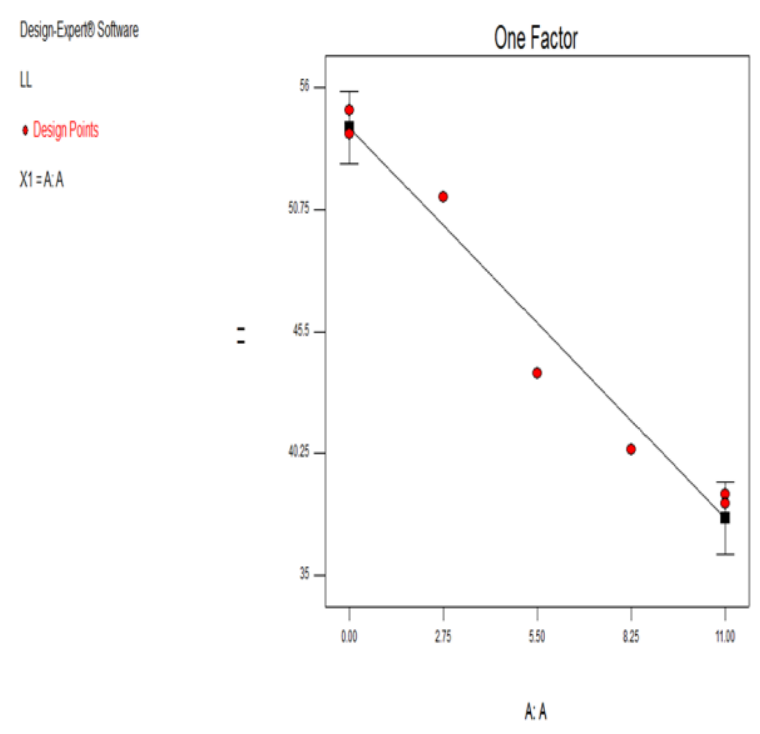

Figure 10: The curve diagram of changes in the liquid limit against the percent of salt

RSM model is given in the following to predict the amount of liquid limit.

$\mathrm{LL}=54.26-1.52 * \mathrm{~A} \quad$ (2)

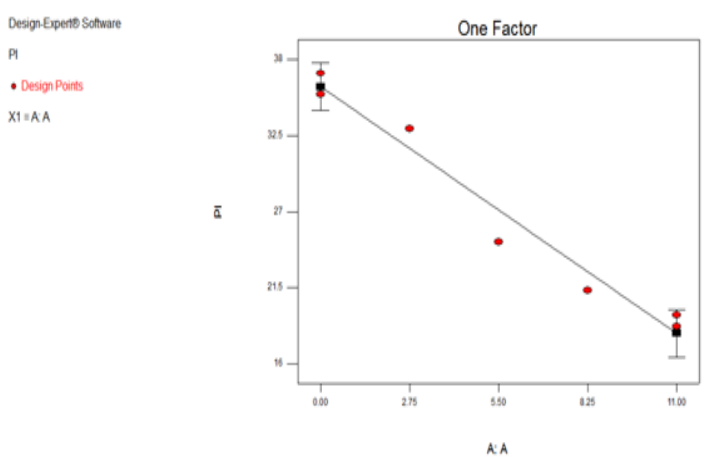

Figure 11: The curve diagram of changes in the plastic index against the percent of salt

RSM model is given in the following to predict the amount of plastic index.

$\mathrm{PI}=36.036-1.622^{*} \mathrm{~A} \quad$ (3)

Results showed a significant reduction in the liquid limit and consequently in the plastic index due to the presence of clayey minerals in the samples while the plastic limit is nearly constant. It can be said that whatever the concentration and percent of salt be higher, the repulsive forces between particles and consequently the dual layer thickness also decreases, and thus the liquid limit goes down. In these conditions, pure repulsive stress resulted from full inflation of dual layer decreases, and consequently the liquid limit changes mainly with the area of clayey plates and cavity fluid chemistry. While, the plastic limit is not sensitive to the change in cavity fluid chemistry and area of clayey plates and also to the chemical-physical effects. The reason for this matter could be that soil adhesion strength expands through the negative cavity pressure in the open cavity fluid and increasing the amount of salt in samples effects on the plastic limit just when it changes the size and distribution of caves and it leads to the development of negative cavity pressure. So, in many cases a gradual increase in the plastic limit is observed along with the increase in concentration. In general, any increase in fluid cavity concentration will lead to the decrease in the liquid level, little change or gradual increasing in plastic limit and consequently decrease in plastic index.

\section{Density Test}

Density curve was drawn for each sample by implementing density standard proctor test on 
different treatments and the compaction characteristics means the maximum dry unit weight and the optimum moisture of all tested sample were determined by using these curves. Results shows that the optimum moisture varies between 11.5 to 12.5 percent for all amounts of used concentrations. While, the tolerance of $2 \%$ are permitted in all projects related to the optimum moisture content. So, it can be conclude that the impact of various types and accounts of salts used in the optimum moisture content is low and negligible. Also, the scope of changes in the maximum dry unit weight obtained for all types of samples was between 1.3 to $1.5 \mathrm{~g} / \mathrm{cm}^{3}$. It means that the difference between the highest and lowest is less than 5 percent. This amount is also less than the tolerance amount allowed for the maximum dry unit weight. Therefore, it can be concluded that the impact of noted salts on the maximum dry unit weight is also not remarkable. In general, it can be said that the amount and type of soil salinity has no significant impact on the compaction characteristics of soil. Figures 12 and 13 show the outputs related to the software.
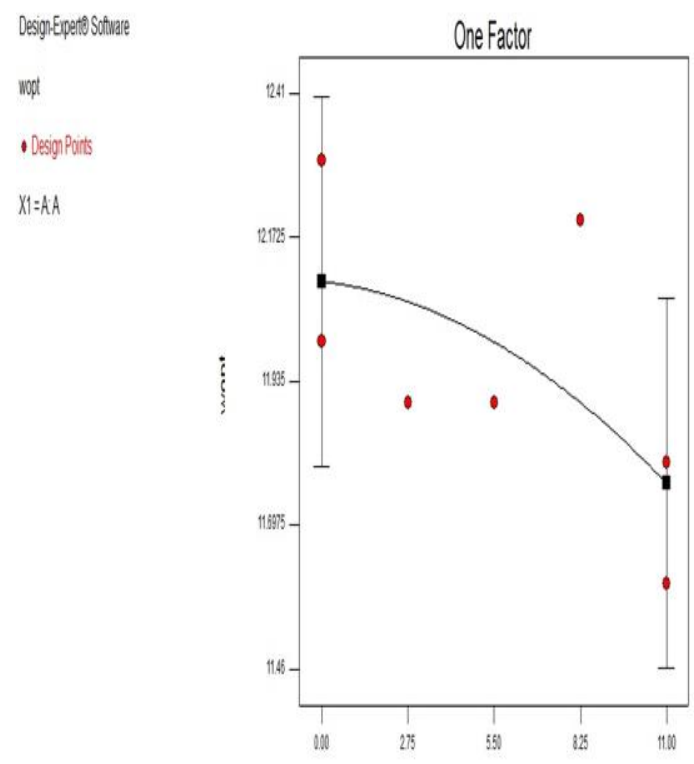

Figure 12: Diagram for changes in optimum moisture by increasing the percentage of salt

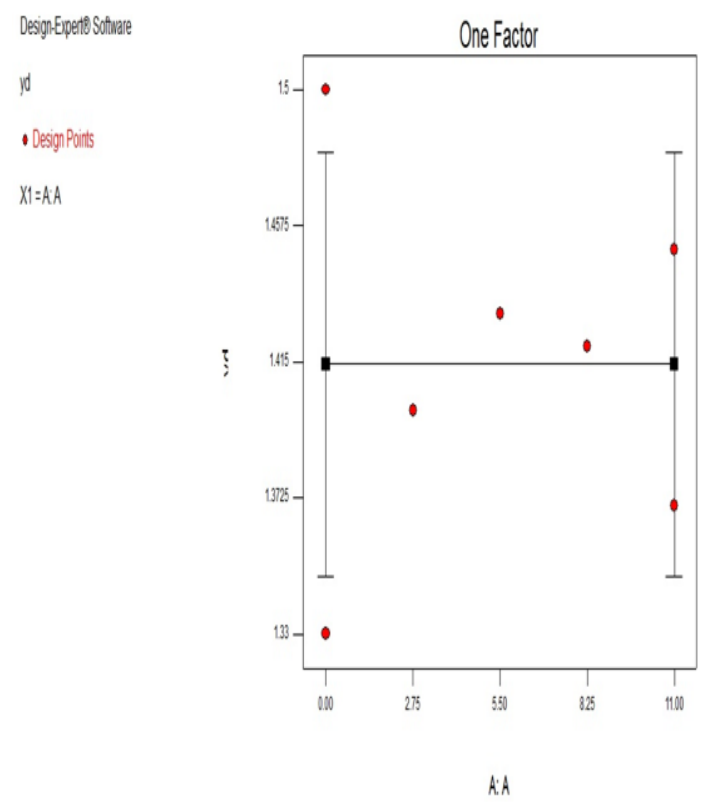

Figure 13: Diagram for changes in dry density by increasing the percentage of salt

\section{Conclusion}

This study has investigated the effect of pore water salinity with percentage and types of salt in the reservoir's water behind the Gotvand dam on the soil used in the clayey core of the dam.

The following conclusions can be inferred and expressed based on the investigations and laboratory tests carried out in this study:

The effect of different concentrations of salt on the optimum moisture content and maximum dry density is very slight and within the allowed tolerance. It means that the amount and type of soil salinity has no significant impact on the compaction characteristics of soils.

Contact of soil with salt waters reduces the plasticity of soil along with decisive reduction in the liquid limit, but there was no difference in the plastic limit of soil.

In the open inflation test, whatever the concentration of salt is higher, the rate of sample's open inflation will be lower. This reduction in the percent of open inflation applies in all points of curve with different percent of moistures.

The percent of open inflation decreases by increasing the percent of moisture. 
Regarding that the optimum soil moisture content is about 12 percent, it can be determined that samples with dryer moisture content from optimum moisture have more inflation than more wet points from optimum point, and this matter is apart from the percent of salt.

Also the samples which were exposed to the higher salinity shows less sensitivity to increasing the moisture content.

Soil behavior in contact with salt waters is mainly predicted with regard to factors: disseminating saline minerals into the soil and reducing the double layer thickness of soil.

Results show that salinity influences on the mechanical characteristics of tested soil. This matter has no destructive impact on the dam body at least in short-term. But, there is a need to investigate the different scenarios in various time cycles, regression periods especially when the salt concentration reduced again, and also to conduct further studies in order to achieve the final results.

\section{Resources}

Abbasi, N., Nazifi, H. and Movahedan, M. 2010. The effects of type and quantity of pore water salinity on clay dispersion. Proceeding of the 4PthP International Conference on Soil Mechanic and Foundation. Nov. 1-2. Tehran. Iran. (in Farsi)

Abbasi, N. and Nazifi, M. H. 2013. Assessment and modification of sherard chemical method for evaluation of dispersion potential of soils. Geotech. Geol. Eng. 31(1): 337-349.

Sadaghiani, M. and Ghadak, H. 2004. The effects of $\mathrm{pH}$ on strength properties of Clay. Proceeding of the 1PstP National Congress of Civil Engineering. May. 14-17. Sharif University. Tehran. Iran. (in Farsi)

Lambe, T. W. 1985. The engineering behavior of compacted clay. ASCE J. Soil Mech. Found. Div. 84, 1-35.

Mitchell, J. K. 1993. Fundamentals of Soil Behavior. John Wiley \& Sons Inc.

Abdullah. W. S., Al-Zoubi, M. S. and Alshibli. K. A. 1997. On the physicochemical aspects of compacted clay compressibility. Can. Geotech. J. 34(4): 551-559.

Van Paassen, L. A. and Gareau. L. F. 2004. Effects of Pore Fluid Salinity on Compressibility and Shear Strength Development of Clayey Soils (Lecture Notes in Earth Sciences). In: Hack, R., Azzam, R. and Charlier, R. (Eds.) Engineering Geology for Infrastructure Planning in Europe. Springer Pub. 327-340.

Yilmaz, I. 2006. Indirect estimation of the swelling percent and a new classification of soils depending on liquid limit and cation exchange capacity. Eng. Geol. 85, 295-301.

Yukselen-Aksoy, Y., Kaya, A. and Oren, A. H. 2008. Seawater effect on consistency limits and compressibility characteristics of clays. Eng. Geol. 102, 54-61.

Rao, S. M. and Thyagaraj, T. 2007. Swellcompression behaviour of compacted clays under chemical gradients. Can. Geotech. J. 44, 520-532.

Baumgartner, P., Priyanto, D., Baldwin, J. R., Blatz, J. A., Kjartanson, B. H. and Batenipour, H. 2008. Preliminary results of onedimensional consolidation testing on bentonite clay-based sealing components subjected to two pore-fluid chemistry conditions. Report No. NWMO TR-2008-06. Nuclear Waste Management Organization. Toronto. Canada.

Olson. R. E. and Mitronovas, F. 1960. Shear strength and consolidation characteristics of calcium and magnesium illite. Proceeding of the 9PthP National Conference on Clays and Clay Minerals. Oct. 5-8. Purdue University. India. 185-209.

Kenny, T,C, 1967, "then influence of mineral composition of the residual strength of natural sails", in proceedings of the geotechizal conf, oslo, vol, 1, pp,122-129.

chatopad hyaya, p.k, 1972, "Residual sheur strength of some pure day mineral "Ph.D dissertation, Department of civil Eng. University of Alberta Edmonton. D; Maio, C, and Fenelli,.g.b, 1994, "Residual strength of Kolin and bentonite: 
Di Maio, C, 1996 "Exposure of bentonite of salt osmotic and mechanical effects". geotecnique 4b, N0.4, pp695-707.

Mashkouh, Z. (2011). "Investigating the impact of salinity and moisture in mechanical properties of saline soils", M.A. thesis, Yazd university. Abbasi, N., Oveisiha, M. and Movahedan, M. (2013). "Investigating the impact of pore water salinity on the consolidation and compaction behavior of clayey soils", Journal of Agricultural Engineering, No.3, 67-82. 